UJMR, Volume 6 Number 1, June, 2021, pp 175 - 181

ISSN: 2616 - 0668

https://doi.org/10.47430/ujmr.2161.023

Received: $24^{\text {th }}$ May, 2021

Accepted: $09^{\text {th }}$ June, 2021

\title{
Evaluation of the Antibacterial Effectiveness of Some Antiseptics and Disinfectants
}

${ }^{*}$ Aminu, A.I. ${ }^{1}$ and Abdullahi, M.S. ${ }^{1}$

Department of Microbiology,

Faculty of Life Sciences, Bayero University, Kano

*Correspondence author: aishatuaminuibrahim@gmail.com,08054503326

\begin{abstract}
Application of disinfectants and antiseptics continue to be an essential part of infection control practices; as such there is the need for constant evaluation of their effectiveness. The study aimed at evaluating the antibacterial effectiveness of some brands of disinfectants and antiseptics against some bacterial isolates. Two disinfectants-D1 (Sodium hypochlorite $3.85 \%$ ) and D2 (7\% Tar acid, phenol, 2\% cresylic creosote) and two antiseptics-A1 (Chloroxyenol B.PC $48 \% \mathrm{nw} / \mathrm{v}$, oleumpiniaromgticum $8.3 \% \mathrm{w} / \mathrm{w}$ ) and A2 (Dichlorometaxylenol, IPA, terpinol) were selected and their efficacies against Staphylococcus aureus, Pseudomonas aeruginosa, Klebsiella spp and Escherichia coli were determined using agar disk diffusion methods. The potency of the disinfectants was further evaluated against phenol to establish the phenol coefficient (PC). The result revealed that both the disinfectants and the antiseptics inhibited the different test organisms at various concentrations producing higher inhibition zones at higher concentrations $(P=0.001)$ that differ significantly with the type of agent used $(P=0.007)$. Both agents produces higher inhibitions zones against $S$. aureus, Klebsiella spp, E. coli and the least inhibition zones against $P$. aeruginosa. At 100\% concentration, D1 produces the highest inhibition zone of $21 \mathrm{~mm}$ against $E$. coli, while A1produces the highest inhibition zones of $17 \mathrm{~mm}$ against $E$. coli, S. aureus and Klebsiella spp. The result indicated that both disinfectants (D1 and D2) are more effective than phenol and that D1 is more effective than D2 with Pc coefficient of 3.0 and 2.0 against S. aureus and $P$. aeruginosa respectively compared to D2 with a Pc of 2.0 and 1.05 against $S$. aureus and $P$. aeruginosa. The study identifies that both disinfectants and antiseptics especially D1 and A1 were effective against the test isolates except $P$. aeruginosa which was less susceptible.

Key words: Evaluation, Disinfectants, Antiseptics, Bacteria
\end{abstract}

\section{INTRODUCTION}

The rising trend of infectious diseases and the continuous development of antimicrobial resistance by microbial agents continue to pose greater public health challenges. In an attempt to control the growth of microbes on both inanimate objects and living tissues, disinfectants and antiseptics have gained wide acceptance and are used extensively in households, hospitals and other places for various topical and hard-surface applications. Gargi et al. (2015) reiterated that disinfectants and antiseptics are an essential part of infection control practices and aid in the preventing nosocomial infection. Antiseptics are products that destroy or inhibit the growth of microorganisms on living tissues and help prevent infections while disinfectants are similar but are products or biocides used on inanimate objects or surfaces (Nester et al. 2007; Boyce and Pitted, 2002). Depending on their chemical nature, antiseptics and disinfectants can be categorized as alcohols, phenols, halogens, quaternary ammonium compounds (QACs), dyes, aldehydes, peroxygens, heavy metal derivatives etc.

Evaluation of disinfectants or antiseptics refers to the process of establishing documented evidence that a disinfectant or antiseptic will consistently remove or inactivate known or possible pathogens from samples (CDC, 2019). According to Rutala and Weber (2014) the selection of appropriate antiseptic and disinfectant is based on their toxicity, activity in the presence of organic matter, compatibility with the material being treated, type of residue, cost and availability, storage and stability, environmental risk, physical and chemical factors, kinds of microorganism present, concentration and potency with other variables, and biofilm production. 
Some of the numerous methods used to evaluate disinfectants and antiseptics include; Carrier tests, suspension test, capacity test, practical test and in use test. For, example the Rideal Walker method is a type of suspension test that determines the effectiveness of an agent by comparing it with phenol through the establishment of a phenol coefficient.

Studies have established that the mode of action of antiseptics and disinfectants is directed against the microbial cell wall, cytoplasmic membrane, nucleic acid and protein. On their part the microbes develop different strategies to overcome the action of these chemicals. Most importantly, the emergence of resistant microorganisms in hospitals and the community such as methicillin-resistant Staphylococcus aureus and the notorious Pseudomonas aeruginosa resistant strains is already a major problem in patient treatment and infection control. A review by Mcdonnell and Russell (1999) revealed that bacterial resistance to antiseptics and disinfectants could be either a natural property of an organism (intrinsic) or acquired by mutation or acquisition of plasmids (selfreplicating, extrachromosomal DNA) or transposons (chromosomal or plasmid integrating, transmissible DNA cassettes).

Thus as antiseptics and disinfectants are continuously being used to reduce and remove contaminants and infectious agents, it has become necessary from time to time to evaluate their effectiveness against a variety of microbial agents especially pathogens. This will allow selection of an appropriate antimicrobial agent and establish the required effective dilution and the time taken for onset of action which in the long run ensures effective control of infectious diseases. The study aimed at evaluating the antimicrobial effectiveness of some antiseptics and disinfectants.

\section{MATERIALS AND METHODS}

Collection and processing of the disinfectants and antiseptics

Two disinfectants D1 (Sodium hypochlorite $3.85 \%)$ and D2 (7\% Tar acid, phenol, 2\% cresylic creosote) and two antiseptics A1 (Chloroxyenol B.Pc $48 \% \mathrm{nw} / \mathrm{v}$, oleumpiniaromgticum $8.3 \% \mathrm{w} / \mathrm{w}$ ) and A2 (Dichlorometaxylenol. IPA, terpinol) that were commonly used in the hospital and household were purchased and used for the study. All the selected agents were certified by the Nigerian National Agency for Food Drug Administration and Control.

Sterile distilled water was used to prepare different dilutions of the disinfectants/antiseptics solution according to the methods described by Mohamed et al. (2016); Saha et al. (2009). For 100\% concentrations, $10 \mathrm{ml}$ of the disinfectants/antiseptics was withdrawn using a sterile syringe from the original containers and put in a test tube and labeled $100 \%$. To obtain $80 \%$ concentration, $8 \mathrm{ml}$ of the undiluted disinfectant/antiseptic was withdrawn from the package container and transferred to a test tube containing $2 \mathrm{mls}$ of distilled water, mixed thoroughly and labeled. The same procedure was repeated to obtain $60 \%, 40 \%$ and $20 \%$ concentration.

Antibacterial susceptibility testing

Sterile paper discs were prepared according to methods described by Cheesbrough (2006). First, filter discs of $5 \mathrm{~mm}$ were made from Whatman No. 1 filter paper and dispensed in a screw-capped bottle and then sterilized by dry heat in an oven at $140^{\circ} \mathrm{C}$ for 60 minutes. Then, ten (10) sterile discs were incorporated with $0.1 \mathrm{ml}$ of various concentrations of the test solution, such that each disc absorbs approximately $0.01 \mathrm{ml}$ of the test solution.

Four clinical isolates (Staphylococcus aureus, Pseudomonas aeruginosa, Klebsiella spp and Escherichia coli) were obtained from the Department of Clinical Microbiology, Aminu Kano Teaching Hospital, Kano and used as test organisms. The identity of the isolates was confirmed using colonial appearance, Gram's staining and biochemical tests that include; catalase, coagulase, oxidase, indole, citrate utilization, urease and methyl red tests as described by Cheesbrough (2006).

Following identification, the inoculum was standardized according to Cheesbrough (2006) by sub-culturing the isolates onto sterile nutrient agar plates and incubated at $37^{\circ} \mathrm{C}$ for 24 hours. Using a sterilized wire loop, the overnight cultures were diluted in normal saline $(0.85 \% \mathrm{w} / \mathrm{v})$ such thattheir turbidity matches with 0.5 Macfarland standards $\left(1.0 \times 10^{8} \mathrm{cfu} / \mathrm{ml}\right)$. A sterile swab was then dipped into the standardized inoculum and then swabbed on the surface of already prepared Muller Hinton agar plates and allowed to dry for 5 minutes.

The antimicrobial activity assay was carried out according to standard disk diffusion technique described by Cheesbrough (2006). Using sterile forceps, discs impregnated with the different dilution of different antiseptics/disinfectants prepared above were placed on each of the Mueller Hinton agar plates inoculated with the test organisms. The plates were then incubated in an inverted position at $37^{\circ} \mathrm{C}$ for 24 hours. After which, the zone of inhibition was observed and recorded. 
Phenol coefficient test

Rideal-Walker test was used to determine the Phenol Coefficient of the two disinfectants and was carried out according to CDC (2019). Five (5) different dilutions of phenol were prepared $(1: 90,1: 95,1: 100,1: 105$ and 1:110) and another 5 dilutions of the test disinfectants D1 and D2 (1:100, 1:200,1:300, 1:400 and 1:500). Then $0.1 \mathrm{ml}$ of 24 hour broth cultures of Pseudomonas aeruginosa and Staphylococcus aureus was added to $5 \mathrm{mls}$ of the different dilutions of the phenol and test dilutions. Then at intervals of 5,10 and 15 minutes, $0.2 \mathrm{mls}$ from each dilution of phenol and test solution were withdrawn and sub-cultured into the fresh nutrient broth and incubated at $37^{\circ} \mathrm{C}$ for 24 hours. Following incubation, the presence or absence of growth in each broth was recorded.The Phenol coefficient (Pc) of the test solution was calculated by dividing the highest dilution of the disinfectant that kills the organisms in 10 minutes by the highest dilution of phenol that kills the same organism in 10 minutes.

Interpretations of Rideal Walker test:

$\mathrm{PC}=1$ indicates that test disinfectant have the same efficiency as phenol

$\mathrm{Pc}>1$ indicates that test disinfectant is more potent than phenol

$\mathrm{Pc}<1$ indicates that test disinfectant is less potent than phenol

\section{RESULTS}

Table 1 show that all the test solutions exhibited antibacterial activity against all the test isolates at different concentrations, although they produced lower inhibition zones against $P$. aeruginosa. The Table also revealed that the activity of the test solutions was higher with increasing concentration and that it was highest at $100 \%$ concentration of the test solutions against all the isolates $(P=0.001)$. At the concentration of $100 \%$ D1 exhibited the highest zone of inhibition of $21 \mathrm{~mm}$ against $E$. coli and the lowest inhibition zone of $17 \mathrm{~mm}$ against $P$. aeruginosa. In contrast, at a $20 \%$ concentration D1 produces a lower inhibition zone of $10 \mathrm{~mm}$ against $E$. coli and $7 \mathrm{~mm}$ inhibition zone against the other three isolates (Table 1).

The result of the study also indicated a significant difference in the activity of the different agents used and that D1 exhibited higher antibacterial activity against the test isolates than the other agents $(P=0.007)$ (Table
1). The Table revealed that among the two disinfectants studied D1 produces higher inhibition zones against all the isolates at all concentrations compared with D2. For instance at the concentration of $100 \%$ D1 produces an inhibition zone of $21 \mathrm{~mm}, 18 \mathrm{~mm}, 13 \mathrm{~mm}$ and $17 \mathrm{~mm}$ against $E$. coli, S.aureus, P.aeruginosa and Klebsiella spp whereas at the same concentration D2 produces an inhibition zone of $17 \mathrm{~mm}, 15 \mathrm{~mm}, 11 \mathrm{~mm}$ and $16 \mathrm{~mm}$ against $E$. coli, S. aureus, $P$. aeruginosa and Klebsiella spp respectively. Even at 20\% concentration D1 exhibited activity against all the test isolates whereas D2 exhibited activity against only one (Klebsiella spp) out of the four test isolates.

Similarly, Table 1 shows that among the two antiseptics, A1 produces higher inhibition zones against all the four isolates compared with $\mathrm{A} 2$. For example, at the $100 \%$ concentration, A1 produces inhibition zones of $11 \mathrm{~mm}, 17 \mathrm{~mm}$, $10 \mathrm{~mm}$ and $17 \mathrm{~mm}$ against $E$. coli, S. aureus, $P$. aeruginosa and Klebsiella spp respectively, whereas A2 produces lower inhibition zones at the same concentration of $15 \mathrm{~mm}, 16 \mathrm{~mm}, 11 \mathrm{~mm}$ and $10 \mathrm{~mm}$ against $E$. coli, S. aureus, $P$. aeruginosa and Klebsiella spp respectively (Table 1).

Table 1 further revealed that at all concentrations both the disinfectants and antiseptics exhibited higher antibacterial activity against $E$. coli, S. aureus and Klebsiella spp producing higher zones of inhibitions and less active against $P$. aeruginosa producing lower inhibition zones. For instance, at 100\% D1 produces inhibition zones of $17 \mathrm{~mm}$ to $21 \mathrm{~mm}$ against the three isolates but an inhibition zone of $13 \mathrm{~mm}$ against $P$. aeruginosa. Similarly at the same concentration D2 exhibited higher zones of inhibition ranging from $15 \mathrm{~mm}$ to $17 \mathrm{~mm}$ against the three isolates and a lower inhibition zone of $11 \mathrm{~mm}$ against $P$. aeruginosa. The antiseptics $A 1$ and $A 2$ similarly exhibited higher inhibition zones against the three isolates and less activity against $P$. aeruginosa (Table 1 ). Of interest is that, at a lower concentration of $20 \%$ D2, A1 and A2 exhibited no activity against $P$. aeruginosa.

Table 2 shows that both the two disinfectants D1 and D2 were more effective than phenol and D1 is more effective than D2. Specifically, D1 had a higher PC coefficient of 3.0 and 2.0 against $S$. aureus and $P$. aeruginosa than D2 which had $\mathrm{a} P \mathrm{Pc}$ of 2.0 and 1.05 against $S$. aureus and $P$. aeruginosa respectively. 
Table 1: Antibacterial Activity of some Disinfectants/Antiseptics against Bacterial Isolates

\begin{tabular}{llllll}
\hline Disinfectant/ & Dilutions & \multicolumn{5}{l}{ Diameter Zone of Inhibition (mm) } \\
\cline { 2 - 6 } Antiseptic & & E. coil & S. aureus & P.aeruginosa & Klebsiella spp \\
\hline D1 & $100 \%$ & 21 & 18 & 13 & 17 \\
(Sodium & $80 \%$ & 18 & 16 & 11 & 15 \\
3.85\%) & $60 \%$ & 15 & 12 & 9 & 11 \\
& $40 \%$ & 12 & 9 & 8 & 9 \\
D2 & $20 \%$ & 10 & 7 & 7 & 7 \\
(7\% Tar acid, phenol, & $100 \%$ & 17 & 15 & 11 & 16 \\
2\% cresylic creosote) & $80 \%$ & 13 & 11 & 10 & 14 \\
& $60 \%$ & 10 & 9 & 9 & 11 \\
A1 & $40 \%$ & 8 & 7 & 7 & 9 \\
(Chloroxyenol & $20 \%$ & - & - & - & 17 \\
4.8\%w/v, & $100 \%$ & 17 & 17 & 10 & 15 \\
oleumpiniaromaticum & $80 \%$ & 15 & 15 & 10 & 13 \\
8.3\%w/w) & $60 \%$ & 12 & 11 & 8 & 9 \\
& $40 \%$ & 9 & 10 & 7 & \\
A2 & $20 \%$ & 8 & 9 & - & 9 \\
(Dichlorometaxylenol. & $100 \%$ & 15 & 16 & 11 & 8 \\
IPA, terpineol) & $80 \%$ & 12 & 15 & 10 & 7 \\
& $60 \%$ & 10 & 13 & 9 & - \\
\hline
\end{tabular}

Key: D=Disinfectant; A=Antiseptic; E=Escherichia; S=Staphylococcus; P=Pseudomonas.

Note: Zones of inhibitions vary significantly $(p<0.05)$ against, i) concentration of agents/solutions: $F(4,75)=$, 30.741; $P=0.001$ and ii) type of agents: $F(4,79)=3.896 ; P=0.00$

Table 2: Bactericidal Efficiency and the Phenol Coefficientof Disinfectants against Test Isolates

\begin{tabular}{|c|c|c|c|c|c|c|c|}
\hline \multirow{3}{*}{$\begin{array}{l}\text { Disinfecta } \\
\text { nt }\end{array}$} & \multirow{3}{*}{$\begin{array}{l}\text { Dilutio } \\
\mathrm{n}\end{array}$} & \multicolumn{6}{|c|}{ Contact time (minutes) with the test organism } \\
\hline & & \multicolumn{3}{|c|}{ Staphylococcus aureus } & \multicolumn{3}{|c|}{ Pseudomonas aeruginosa } \\
\hline & & $5 \mathrm{~min}$ & $10 \mathrm{~min}$ & $15 \mathrm{~min}$ & $5 \mathrm{~min}$ & $10 \min$ & $15 \mathrm{~min}$ \\
\hline \multirow[t]{5}{*}{ D1 } & $1: 100$ & & & 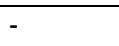 & 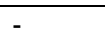 & - & 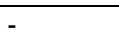 \\
\hline & $1: 200$ & + & - & - & + & - & - \\
\hline & $1: 300$ & + & - & - & + & + & - \\
\hline & $1: 400$ & + & + & - & + & + & - \\
\hline & $1: 500$ & + & + & - & + & + & + \\
\hline \multirow[t]{9}{*}{ Phenol } & $1: 90$ & - & - & - & - & - & - \\
\hline & 1:95 & + & - & - & + & - & - \\
\hline & $1: 100$ & + & - & - & + & - & - \\
\hline & 1:105 & + & + & - & + & + & - \\
\hline & $1: 110$ & + & + & + & + & + & + \\
\hline & & \multirow{2}{*}{\multicolumn{6}{|c|}{$\begin{array}{c}\text { Phenol coefficient }=3.0 \\
\text { Contact time (minutes) } \text { with the test organism }\end{array}$}} \\
\hline & & & & & & & \\
\hline & & \multicolumn{3}{|c|}{ Staphylococcus aureus } & \multicolumn{3}{|c|}{ Pseudomonas aeruginosa } \\
\hline & & $5 \mathrm{~min}$ & $10 \min$ & $15 \min$ & $5 \min$ & $10 \min$ & $15 \mathrm{~min}$ \\
\hline \multirow[t]{5}{*}{ D2 } & $1: 100$ & - & - & - & + & - & - \\
\hline & $1: 200$ & + & - & - & + & + & - \\
\hline & $1: 300$ & + & + & - & + & + & - \\
\hline & $1: 400$ & + & + & + & + & + & + \\
\hline & $1: 500$ & + & + & + & + & + & + \\
\hline \multirow[t]{6}{*}{ Phenol } & $1: 90$ & - & - & - & + & - & - \\
\hline & 1:95 & + & - & - & + & - & - \\
\hline & $1: 100$ & + & - & - & + & + & - \\
\hline & 1:105 & + & + & - & + & + & + \\
\hline & $1: 110$ & & + & + & + & + & + \\
\hline & & \multicolumn{3}{|c|}{ Phenol coefficient $=2.0$} & \multicolumn{3}{|c|}{ Phenol coefficient $=1.05$} \\
\hline
\end{tabular}

KEY: min-minutes 
DISCUSSION

The findings of the study indicated that all the disinfectants and antiseptics used were effective against the various bacterial isolates used. In a similar study, Akani et al. (2018) revealed that both branded and unbranded disinfectants were effective against different test isolates used in their study and earlier reports by Akabueze et al. (2013) also revealed that disinfectants tested in their study were effective for use in the health care facilities.

The study also revealed that the efficacy of the test disinfectants/antiseptics against the test organisms varies significantly with the concentration used $(P=0.001)$ and the type of agent used $(P=0.007)$ resulting in variation in the response of the test organisms. Variations in chemical composition and formulations of the agents used may account for the difference in the antibacterial activity. In a related study Kiyawa (2014) noted that the three disinfectants used in their study differ in their spectrum of activity due to the variations in their chemical compositions and formulations. The CDC (2016) stated that concentration, potency and type of disinfectants are some of the major factors that influence the effectiveness of disinfectant. On their part, microorganisms vary greatly in their resistance to chemical germicides and sterilization process with intrinsic resistance playing a major role (CDC, 2016). Other factors that influence the effectiveness of disinfectants include the number and location of microorganisms, physical and chemical factors (temperature, $\mathrm{pH}$, relative humidity, and water hardness), organic and inorganic matter.

An interesting finding of this study although not surprising was that all the four agents studied were found to be active against the test isolates especially at higher concentrations with minimal variations. Compared with other dilutions, all the test solution at $100 \%$ concentration exhibited higher zones of inhibitions that range from $7-21 \mathrm{~mm}$. This is similar to observations made by Jouda et al. (2016); Saha et al. (2009) who revealed that the higher the concentration the more potent and effective is the disinfectant.

The study revealed that there was a significant difference in the activity of the different agents used and that D1 exhibited higher antibacterial activity against the test isolates compared with the other three agents and that A2 was the least. The high activity of D1 may be related to its composition (sodium hypocholorite-3.3\% m/v) which is known to exert significant bactericidal action on bacteria. Earlier studies by Guimarães et al. (2000) revealed that all strains tested in their study were susceptible to sodium hypochlorite, where as the susceptibility of the strains to phenol and to one quaternary ammonium compound was variable. In a review Mcdonnell and Russell (1999) explained that hypochlorite is one the most important chlorine-releasing agents (CRAs) which are highly active oxidizing agents that destroys the cellular activity of proteins with deleterious effects on bacterial DNA that involve the formation of chlorinated derivatives of nucleotide bases, disruptive oxidative phosphorylation andother membraneassociated activity. They further expounded that at higher concentration and depending on CRAs could be sporicidal or virucidal.

The high activity of the disinfectants against the test isolates in the study was further supported by comparing it with phenol. Among the two disinfectants, D1 had a higher Pc of 3.0 and 2.0 against $S$. aureus and $P$. aeruginosa while D2 had a Pc of 2.0 and 1.05 against $S$. aureus and $P$. aeruginosa. This finding supports earlier observations by William et al. (2000) who expounded that the higher the Pc the more potent is the disinfectant.

The findings of this study further shows that at all concentrations both the disinfectants and antiseptics exhibited higher antibacterial activity against $E$. coli, S. aureus and Klebsiella spp producing higher zones of inhibitions and less active against $P$. aeruginosa producing lower inhibition zones or no activity at all. The less activity against $P$. aeruginosa observed in this study may be explained according to CDC (2019); Denyer and Russell (2004) who stated that $P$. aeruginosa is significantly more resistant to a variety of disinfectants in its naturally occurring state than other cells subcultured on laboratory media due to it being gram-negative and possessing outer membrane that acts as a barrier to the uptake of disinfectants. Furthermore, Todar (2004) explained that with its natural habitat in the soil and living in association with the bacilli, actinomycetes and moulds, $P$. aeruginosa has developed resistance to various naturallyoccurring antibiotics. This possibly makes $P$. aeruginosa resistant to other antimicrobial agents including disinfectants and antiseptics as evidenced in this study as all the agents studied exhibited lower inhibition zones against it or even recorded no activity at lower concentrations. 
Subedi et al. (2018) revealed that $P$. aeruginosa strains had different disinfectant resistance gene profiles and all strains possessed the sugE2, sugE3 and an emrE (qacE) gene with $46 \%$ of isolates possessing the sugE1 and qacEdelta1 disinfectant resistance genes. In a related study, Pseudomonas maintains antibiotic resistance plasmids, both R-factors and RTFs, and itcan transfer these genes utilizing bacterial mechanisms of horizontal gene transfer (HGT), mainly transduction and conjugation. Earlier studies by Guimarães et al. (2000) revealed that $P$. aeruginosa strains were resistant to the antibiotic agents, as well as to the QAC and phenols and concluded that due to the capacity of surviving in unfavorable environmental conditions and to the high resistance to antibiotic agents, antiseptics and disinfectants, $P$. aeruginosa continues to be an important pathogen in hospital-acquired infections mainly respiratory and urinary infections.

\section{REFERENCES}

Akani, N. P., Williams, J. O. and Nnamdi, A. U. (2018).Comparative Studies on Effectiveness of Branded and Unbranded Disinfectants on $E$. coli and Staphylococcus Species.South Asian Journal of Research in Microbiology, 2 (4): 1-8. DOI: 10.9734/SAJRM/2018/v2i430071.

Boyce, J. M. and Pittet, D. (2002). Healthcare Infection Control Practices Advisory Committee; HICPAC/SHEA/APIC/IDSA Hand Hygiene Task Force. Guideline for Hand Hygiene in Health-Care Settings. Recommendations of the Healthcare Infection Control Practices Advisory Committee and the HICPAC/SHEA/APIC/IDSA Hand Hygiene Task Force. Society for Healthcare Epidemiology of America/Association for Professionals in Infection Control/Infectious Diseases Society of America. MMWR Recomm Rep, 51 (RR16):

1 CE4.https: //pubmed.ncbi.nlm.nih.gov/ $12418624 /$.

Centre for Disease Control (CDC) (2019).Guideline for Disinfection and Sterilization in Healthcare Facilities, 2008.

https: / /www.cdc.gov/infectioncontrol/ guidelines/disinfection/

UMYU Journal of Microbiology Research

\section{CONCLUSION}

The study indicated that all the disinfectants and antiseptics used were effective against the various bacterial isolates used and that the efficacy of the test disinfectants/antiseptics against the test organisms varies significantly with the concentration used $(P=0.001)$ and the type of agent used $(P=0.007)$. The study revealed that compared with the other three agents D1 (Sodium hypochlorite 3.85\%) exhibited higher antibacterial activity against the test isolates and had higher Pc of 3.0 and 2.0 against $S$. aureus and $P$. aeruginosa. The findings of this study further shows that at all concentrations both the disinfectants and antiseptics exhibited higher antibacterial activity against $E$. coli, S. aureus and Klebsiella spp and less active against $P$. aeruginosa. The study identifies that the disinfectants and antiseptics studied were effective and that correct dilutions should be strictly adhered to for optimum decontamination and infection control practices.

Cheesebrough, M. (2006).District laboratory practice in tropical countries.Part 2. London, Cambridge University Press.

Denyer, S.and Russell, A. D. (2004).Nonantibiotic antibacterial agents: mode of action and resistance. In D. S. P. Denyer, N. A., Hodges and S. P. Gorman (Eds.),Hugo and Russell's Pharmaceutical Microbiology(7th ed., pp. 306-322). United Kingdom, Gosport: Blackwell Science Publishers.

Akabueze, E., Obi, S., Nwankwo, E. and Ojoru, A. (2013). Evaluation of Efficacy of Disinfectants Using Standard Methods in Healthcare Facilities in Kogi state, North central Nigeria. Asian Journal of Biomedical and Pharmaceutical Sciences, 3 (27);

2013.https: / /www.alliedacademies.org /articles/evaluation-of-efficacy-ofdisinfect

Gargi R., Harshad, V., Mukesh, P. and Jadhav, R. (2015). Efficacy of Some Antiseptics and Disinfectants: A Review. International Journal of Pharmacy and Pharmaceutical Research, 4 (4): 182197. www.ijppr.humanjournals.com.

Guimarães, M, A., Tibana, A., Nunes, M. P. and Santos, K. R. N. (2000). Disinfectant and Antibiotic Activities: A Comparative Analysis in Brazilian Hospital Bacterial Isolates. Brazilian Journal of Microbiology, $31 \quad$ (3): 192- 
198. https: //dx.doi.org/10.1590/S151783822000000300008

Hugo, W.B. Hugo and Russell, A. D. (2004). Hugo and Russell's Pharmaceutical Microbiology (7th ed.). United Kingdom, Gosport: Blackwell Science Publishers.

Mohamed, M. J., Zuhair, D. and Mohammed, A. (2016). The Antibacterial Effect of some Household Detergents against Staphylococcus aureus. Int $\mathrm{J}$ CurrMicrobiol App Sci, 5 (2): 459-463. doi: http: //dx.doi.org/10.20546/ijcmas.

Kiyawa, S. A., Umar, S., Kutama, A.S. and Datti, Y. (2014).In-Vitro Antifungal Efficacy Evaluation of Parazone, Methylated Spirit, and Hydrogen Peroxide on Cercosporapenniseti (Chupp) the Causal Agent of the Millet Cercospora Leaf Spot.International Research Journal of Public and Environmental Health, 1 (8): 165-169. http://dx.doi.org/10.15739/irjpeh.003

Mcdonnell, G. and Russell, D. (1999). Antiseptics and Disinfectants: Activity, Action, and Resistance.Clinical Microbiology Reviews, 12 (1):147179.http: //cmr.asm.org/.

Nester, E. W., Anderson, D. G., Roberts Jr, C. E. Nester, M. T. (2007).Microbiology: $A$
Human Perspective(5th ed.).New York: McGraw-Hill Publishing Co.

Rutala, W. and Weber, D. (2014). Infection control: The role of disinfection and sterilization. Journal of Hospital Infection, 43Suppl (4):S43-55. DOI: 10.1016/S0195-6701(99)90065-8.

Saha, A. K., Haque, M. F. Karmaker, S. and Mohanta, M. K. (2009). Antibacterial Effects of some Antiseptics and Disinfectants.J. Life Earth Sci, 3-4: 1921DOI: $10.3329 /$ jles.v3i0.7440.

Subedi, D., Vijay, A. K. and Willcox, M. (2018).Study of Disinfectant Resistance Genes in Ocular Isolates of Pseudomonas aeruginosa.Antibiotics, 7 (88):

7.doi:10.3390/antibiotics7040088.

Todar, K. (2004). Today's Online Textbook of Bacteriology. Madison, University of Wisconsin.www.textbookofbacteriology .ne

William A. R., Barbee, S. L., Aguiar, N. C. and Sobsey, M. D. (2000). Antimicrobial Activity of Home Disinfectants and Natural Products Against Potential Human Pathogens. Infection Control \& Hospital Epidemiology, 21 (1): 33-38. DOI: https: //doi.org/10.1086/501694. 